\section{LA DISCORDIA DE ILÍADA EN LA NOVELA AQUILES O EL GUERRILLERO YEL ASESINO DE CARLOS FUENTES}

\author{
Graciela C. Zecchin de Fasano* \\ Recebido em:13/05/2019 \\ Aprovado em: 03/06/2019
}

\begin{abstract}
RESUMEN: En la historia de la crítica literaria, la lectura de Ilíada como un poema que transmitía las atrocidades de la guerra confrontó en numerosas ocasiones con su recepción como una composición marcial, que incitaba ostensiblemente a la muerte gloriosa de los jóvenes. Semejante contradicción hermenéutica indica claramente el carácter controvertido e inquietante de Aquiles, en cuya configuración juega un papel esencial el concepto de discordia. La novela póstuma de Fuentes que lleva como título el nombre del personaje protagonista de Ilíada se funda en la estética homérica de la discordia violenta como eje compositivo. Nos proponemos analizar cómo Fuentes logró en su novela conferir un carácter "latinoamericano" al conflicto iliádico, de un modo tan homérico que la muerte del protagonista se convierte en una lección de piedad.
\end{abstract}

PALABRAS CLAVE: Aquiles; Ilíada; Homero; Carlos Fuentes; novela latinoamericana.

\section{THE DISCORD OF THE ILIAD IN THE NOVEL AQUILES O EL GUERRILLERO Y EL ASESINO BY CARLOS FUENTES}

* Professora Titular de Grego, Centro de Estudos Helênicos, Faculdade de Humanidades e Ciências da Educação, Universidade Nacional de La Plata.

gzecchin@hotmail.com

\footnotetext{
ABSTRACT: In the history of literary criticism, the reading of the Iliad as a poem that conveyed the atrocities of war confronted on numerous occasions with its reception as a martial composition, which ostensibly incited the glorious death of young people. Such a hermeneutical contradiction clearly indicates the controversial and disturbing character of Achilles in whose configuration the concept of discord plays an essential role. The posthumous novel of Fuentes that takes as its title the name of the main character of Iliad is based on the Homeric aesthetic of violent discord as a compositional axis. We intend to analyze how Fuentes managed in the iliadic conflict in his novel to confer it a very
} 
"Latin American" feature, in such a Homeric way that the death of the protagonist becomes a lesson in piety.

KEYWORDS: Achilles; Iliad; Homer; Carlos Fuentes; Latin American Novel.

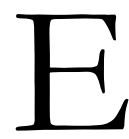

n la historia de la crítica literaria, la lectura de Ilíada como un poema que transmitía las atrocidades de la guerra confrontó en numerosas ocasiones con su recepción como una composición marcial, que incitaba ostensiblemente a la muerte gloriosa de los jóvenes. ${ }^{1}$ Semejante contradicción hermenéutica indica claramente el carácter controvertido e inquietante de Aquiles en cuya configuración juega un papel esencial el concepto de Éris o discordia. La novela póstuma de Carlos Fuentes que lleva como título el nombre del personaje protagonista de Ilíada se funda en la estética homérica de la discordia violenta como eje compositivo.

Nos proponemos analizar cómo Fuentes logró en su novela conferir un carácter "latinoamericano" al conflicto iliádico, de un modo tan homérico que la muerte del protagonista se convierte en una lección de piedad. En consecuencia, el concepto de recepción será utilizado en un sentido amplio, es decir como una lectura, que Fuentes no realizará de ningún modo pasivo, sino de un modo dialéctico, polémico, o como sostiene Heidmann (2003, p. 9), citando a Paul Celan, como una reescritura del mito, en la que: "le processus de création littéraire est un incessant travail de réécriture-subversion de l'héritage en vue d'un inconnu".

Aquiles o el guerrillero y el asesino, publicada en 2016, propone desde su título una dicotomía trágica. Contiguo al inevitable apego a la intertextualidad homérica que instala el nombre "Aquiles" ubicado en primer lugar, se abre la disociación disyuntiva marcada por el coordinante "o" en el sintagma nominal del título, que indica un argumento basado no en un guerrero y su contrincante, sino en un "guerrillero", con la carga ideológica que este derivativo implica. Tampoco se refiere en paridad de condiciones a una confrontación entre héroes, el mero uso de la palabra "asesino" impone que Aquiles será o ya fue asesinado, que su oponente no es un héroe y su nombre no importa. Se nos propone una lectura de la discordia como disyunción y en el uso del artículo determinante el título de la novela instala, además, el valor paradigmático del mito (el guerrillero/el asesino). ${ }^{2}$ De los conocimientos heroicos, ${ }^{3}$ Fuentes ha elegido para su personaje el ineluctable conocimiento de la muerte.

\footnotetext{
${ }^{1}$ Como ha notado Alexander (2015, p. 258) constituye una ironía de la historia que Ilíada al narrar tan fehacientemente las atrocidades de la guerra se convirtiese en una epopeya marcial, cuando Homero insiste en su carácter de catástrofe destructiva.

${ }^{2}$ Tal como señala Ortega, el editor de la novela, Fuentes expresa en ella la imposibilidad de una fraternidad latinoamericana. La disyunción del sintagma que la titula es la imagen más contundente. Cf. Reportaje a Julio Ortega, diario Clarín 16/05/2016.

${ }^{3}$ Sobre la experiencia heroica como conocimiento de la propia muerte, sus circunstancias o su momento, cf. Mueller (1978, p. 105-23), también Austin (1978, p. 70-84), reformulado por Nagy (1999, p. 1-15).
} 
Las razones por las cuales el máximo héroe épico pueda considerarse modelo para la agonal confrontación entre los personajes del guerrillero Carlos Pizarro Leongómez y de Kike su sicario asesino, entroncan con la imposibilidad de expresar lo latinoamericano por sí, aún en el marco de un notable desencanto de su escritor.

Entre las singularidades de esta novela se hallan unas palabras preliminares de la mujer de Fuentes, la periodista Silvia Lemus, quien explica que el escritor había trabajado los últimos 20 años de su vida en este texto, sin embargo no había querido publicarlo hasta que el conflicto con la guerrilla colombiana no hubiera cesado. Silvia Lemus consideró - acaso ilusoriamente - en 2016, que ese conflicto había llegado a su fin, y aceptó su publicación a cargo de Julio Ortega en el Fondo de Cultura Económica y Alfaguara.

Una síntesis de su argumento sorprende por la simplicidad que pareciera conllevar, aunque el desarrollo de la trama no posee linealidad. La novela narra el asesinato del guerrillero colombiano Carlos Pizarro Leongómez, uno de los líderes de movimiento llamado M-19, que aconteciera el 26 de abril de 1990 en un vuelo de la aerolínea Avianca desde Bogotá hacia Barranquilla. Como Ilíada, la novela expone la cólera de un Aquiles colombiano confrontado con su destino en una trama llena de patetismo.

Respecto de la simplicidad de la trama, resulta evidente que Fuentes realiza una apropiación de la épica clásica en la que también está presente la calificación aristotélica sobre la trama de Iliada como haploûn kai pathetikón, "simple y patética" (Poética, 1459b13-14). La lectura receptiva de Fuentes no consiste en la mera comparación entre su versión de Aquiles y el personaje homérico, tampoco deriva en una inocua utilización del pasado como archivo o reservorio, sino que produce un proceso de selección simbólica que se apropia del pasado, lo transforma, le concede densidad y una relevancia similar a la del prestigio homérico. ${ }^{4}$

Desde este marco teórico, intentaremos explicar las particularidades genéticas de la novela, su composición anular, su versión de un heroísmo moderno, el modo en que representa la vulnerabilidad heroica y la discordia como componente social.

\section{UN POCO DE HISTORIA TEXTUAL: ENTRE EL ANÁLISIS GENÉTICO Y UNA ECDÓTICA MODERNA}

El texto de Fuentes guarda una coherencia inusitada con los poemas homéricos y no por decisión personal, sino por el azar del destino. Se trata de un texto editado con posterioridad a la muerte de su autor por un editor amigo. Sin embargo, como en el caso de Homero, e independientemente de la crítica genética que pudiera hacerse, el texto definitivo no es de su autor, ya no le pertenece, ha sido incautado por su editor, casi al modo en que los alejandrinos incautaron el texto homérico, o tal como las ediciones politikaí produjeron. ${ }^{5}$

\footnotetext{
${ }^{4}$ Perilli (2001) aplica a la narrativa de Fuentes dos categorías vigentes para esta novela póstuma: la categoría de "épica crítica" - una revisión del relato nacional fundacional - y la categoría de "novela social" - un estudio de la condiciones colectivas gestadas por el relato fundacional. Ambas categorías claramente visibles en los relatos ubicados en México, operan también en la novela que nos ocupa. ${ }^{5}$ Es decir, las ediciones realizadas en distintas ciudades, conforme la enorme difusión de Homero en el mundo antiguo.
} 
El editor de la novela, Julio Ortega, también responsable del prólogo al cual titula "Aquiles, entre la crónica y la ficción", ubica de este modo uno de los problemas hermenéuticos del texto, como lo es el de su vinculación con el acontecer histórico contemporáneo del narrador/autor y la ficcionalización de ese acontecer en la interpretación narrativa. ${ }^{6}$ Según Ortega, tras largos años de amistad académica, siempre le interesó saber el proceso creativo de las novelas de Fuentes, pero se topó con un autor remiso a hablar de ello, fundamentalmente porque su formulación final las hacía independientes del autor. Como en el caso de los poemas homéricos es difícil saber qué hay de Homero en ellos y también es difícil saber qué hay de Fuentes en sus novelas, sumado al hecho de que ellas eluden toda posibilidad de interpretación basada en la cronología, ya que la fecha de publicación nunca coincide con la de su escritura.

Según Ortega la biblioteca de Fuentes es una suerte de "bibliografía imaginaria" de América Latina, en cuyo tomo 15 el autor se propuso gestar una trilogía narrativa bajo el título Crónicas de nuestro tiempo. Su proyecto quedó incompleto: la primera se tituló Diana o La cazadora solitaria y fue publicada en 1994, la segunda no llegó a escribirla e iba a denominarse Prometeo o el precio de la libertad y la tercera, es la que nos ocupa, Aquiles o el guerrillero y el asesino que, como ya se ha mencionado, se publicó en 2016. En esta trilogía Fuentes proyectaba un recorrido temático por la narrativa latinoamericana desde el desencanto de los años 60 , a la tortura y muerte de un joven rebelde de Chiloé - iba a ser el argumento de la novela que no llegó a escribir - hasta su relación con Colombia y su interés particular por uno de los episodios más violentos de su historia reciente: la muerte de un líder guerrillero. El hecho aconteció en el preciso momento en que el líder había abandonado las armas para proponerse como candidato a presidente, en unas elecciones democráticas o, como el narrador hace expresar a su personaje de Aquiles, como "cabeza de paz".

El carácter histórico del suceso narrado, su búsqueda de la percepción de simultaneidad, el carácter no finito de un texto incompleto, casi tradicional, elaborado según testigos durante veinte años, sujeto a la edición de otros, son algunos de sus rasgos netamente homéricos, por no mencionar el problema del tratamiento del tiempo. ${ }^{7}$

\footnotetext{
${ }^{6}$ Entre las peculiaridades de la narrativa latinoamericana, González Echevarría (1990, p. 18) destaca su inspiración de cuño antropológico y en la historia contemporánea. La necesidad de registrar un modo discursivo que cumpla las veces de archivo aparece desde el epígrafe de Fuentes que el crítico utiliza, para aseverar: "The Archive is a modern myth based on an old form, a form of the beginning (...) This is why a kind of archive usually containing an unfinished manuscript and an archivist-writer, appears with such frequency in modern novels". La observación teórica de González Echevarría se cumple en forma exógena en esta novela de Fuentes, cuyo manuscrito quedó inconcluso y cuyos archivos fueron consultados por Ortega para la edición.

${ }^{7}$ El período en que comenzó la novela fue de arduo trabajo, porque Fuentes había iniciado las filmaciones para la BBC de El espejo enterrado, luego convertido en libro (1992), y había publicado su novela con título romano Diana, pero lo más importante fue su coincidencia con Carlos Pizarro, el protagonista de la novela que nos ocupa, en cuanto a su adhesión a las revoluciones por cuestiones éticas.
} 
Su editor se topó al menos con tres estructuras posibles: en una primera versión, Pizarro es Aquiles en un grupo guerrillero ilustrado, que roba la espada de Bolívar tal como se robó el Paladión en el mundo antiguo, en una intencional simbolización de la acción. Una segunda versión apuntaba al drama de la familia cuyos hijos habían optado por la guerrilla. Un tercer esquema - quizá también temprano - trazaba un paralelo entre Aquiles y su asesino. Ortega confesó: "Armé un rompecabezas sin imagen", sin embargo, su tarea no implicó una tergiversación de los propósitos de su autor:

Carlos había dejado más o menos diseñado el armado del relato. No tuve que escribir nada. Había una ruta que había que poner en limpio: anecdótica, cronológica, de desarrollo de la complejidad del tema. Lo extraordinario es que el asesino es alumno de la mamá del héroe. (Respuesta de Ortega, reportaje diario Clarín 26/05/2016)

En 1994, Fuentes preparó lo que llamó un "second draft", un segundo borrador. Se trata de 33 folios tipeados en máquina de escribir, cuya primera página es una suerte de índice. ${ }^{8}$ Ortega infiere que una de las crisis escriturales del autor fue el intento de abordar como mexicano el drama de narrar los sucesos de una violencia extranjera, tan ajena como la de la guerrilla colombiana, el desafío de proveer a su personaje de un lenguaje, pero también las maniobras de selección del pasado abordado. En el archivo de Fuentes, Ortega encontró un ensayo de Darío Villamizar titulado "Carlos Pizarro, primer paso a la Paz", que debe haberle confirmado la nobleza del personaje histórico y debe haber validado su diseño como otro "Aquiles". De este modo, produjo una novela latinoamericana en la que la violencia no fuese un fin último y sin razón, sino como en la Ilíada el vasto mensaje de una conciliación humana. ${ }^{9}$

\section{UNA COMPOSICIÓN ANULAR}

Fuentes se enfrentó a un problema compositivo que en el nivel discursivo se resolvió al modo épico, en la famosa Ringkomposition de cuño oral. La trama entera de la novela se topa con un problema que Ilíada elabora por elusión: dónde ubicar la muerte de su héroe. Homero opta por la versión indirecta, por exacerbar los tonos funerales de las muertes ajenas de modo que, sin narrar el funeral de Aquiles, su muerte sea omnipresente: en la profecía y en la posición especular en que cada guerrero va sustituyendo al anterior. La secuencia compuesta por Sarpedón, Patroclo, Héctor no requiere completar el nombre final.

Oportunamente, Fuentes coloca al narrador como testigo de la muerte de su Aquiles al inicio de la novela y este hecho es una concesión de extrema verosimilitud al episodio. Se recupera al final el mismo momento, pero para enfocarlo desde el sicario, quien también

\footnotetext{
${ }^{8}$ Cf. Fuentes (2016, p. 18).

${ }^{9}$ Fuentes recupera el mensaje humano ínsito en Ilíada. Sobre las lecturas erradas de Ilíada como poema belicista cf. Alexander (2015, p. 60-86), sobre el humanismo implícito en el cierre del poema, Zecchin de Fasano (2000, p. 57-68) y (2002, p. 109-28).
} 
muere. Ocupadas la apertura y el cierre por el asesinato, el tiempo narrado entre ellos es naturalmente retrospectivo, analéptico, débilmente lineal.

En opinión del editor, que debió seguir notas del autor y, en un ejercicio de ecdótica moderna, introducir variantes de una a otra redacción, el manuscrito de Aquiles parece una parábola de Latinoamérica. El líder muere para que haya algún modo de paz. El valor ritual de la muerte heroica sigue presente en su carácter de sacrificio expugartorio. ${ }^{10}$

La novela se abre con tres epígrafes. En primer lugar, el infaltable epígrafe homérico, "Canta, inmortal, la cólera de Aquiles"; en segundo lugar, uno de Carlos Pellicer, "He olvidado mi nombre..." y el tercero es un dicho colombiano anónimo. "En este país cuatro meses pasan como cuatro siglos..." Se divide en diecinueve capítulos. Sin duda, los epígrafes imponen, por una parte, la impronta iliádica: la cólera incontrolable; pero, por otra parte, aportan el despojo del nombre de un personaje que se vuelve un héroe épico con una suerte de epíteto, "Comandante Papito". Carlos Pizarro Leongómez pierde su nombre para poder ser Aquiles en la lectura de Fuentes, también sus compañeros lo pierden y luego, en el tercer epígrafe aparece a partir de un discurso popular uno de los mayores desafíos narrativos de Fuentes: el problema del tiempo. Su intención de superar el carácter sucesivo de la narración lo lleva a definir: "Tiempo es lenguaje - tiempo es construcción del lenguaje".

Si el héroe es por definición el poseedor de un nombre y de un epíteto que constituye el relato embrional de su fama, sin duda, no resulta inocuo que el homérico Paris Alejandro sea desplazado en la novela de Fuentes por un sicario sin apellido que solo recibe el sobrenombre de Kike. La insignificancia del asesino es una de las subversiones polémicas del mito en el relato latinoamericano.

La confrontación del capítulo inicial con el capítulo final expone claramente, cómo desde un yo narrador se edifica la belleza del guerrerro, su presencia nítida en medio del grupo de guardaespaldas, que lo custodiaban "sin amor". El narrador percibe la muerte cercana de su personaje y al igual que Homero lo invoca y le advierte - "Ponte tu casco pronto, ármate ya, no ves qué indefenso estás...” (1, p. 34) - las reflexiones del narrador instalan un contexto funeral acerca de cómo la especie humana advierte a las otras de su exclusiva conciencia de la muerte. ${ }^{12}$ Naturalmente, la presencia divina es desplazada por elementos religiosos católicos, pero parte de la omnisciencia respecto del destino se ubica en el narrador que es espectador de la muerte y advierte al otro, ignorante de su destino, la real situación en la que se halla inmerso. El usufructo de la ironía trágica es otra deuda de Fuentes con el narrador homérico. ${ }^{13}$

\footnotetext{
${ }^{10}$ Cf. Seaford (1995, p. 176) en que argumenta que el poder de la muerte ritual radica en su capacidad de crear solidaridad entre enemigos.

${ }^{11}$ Comentado en el prefacio a cargo de Ortega. Cf. Fuentes (2016, p. 14).

${ }^{12} \mathrm{Cf}$. El famoso apóstrofe del narrador homérico a Patroclo, al que llama népios, ingenuo. Ilíada XVI. 684-687.

${ }^{13}$ Sobre el valor trágico de la ironía, sigue siendo valiosa la discusión de Lowe (1996, p. 520-33). En este caso, la ironía es otra manipulación del pasado desde el conocimiento privilegiado del narrador.
} 
La descripción física del personaje del guerrillero es coherente con la corporalidad épica: "Vigoroso aunque vulnerable, a la vez tierno y amenazante, como si su peligro máximo fuese la necesidad de proteger lo íntimo mediante una coraza de voluntad guerrera." (1, p. 32). La descripción del ataque, quince balas que le dieron en todas las partes desnudas del cuerpo, especialmente en la garganta, se comparece con las descripciones de muertes en Ilíada. La invocación al muerto con el nombre del guerrero iliádico impone también un contenido funeral expreso en la forma hispánica del responso:

- Ha muerto Aquiles -...mi voz tratando de decir la oración, el responso, el poema.

Ha muerto Aquiles.

Lo hirieron en sus talones, su cabeza, su cuello, sus manos, todo lo que él tenía para mostrarle al mundo para que el mundo lo amara, aunque el mundo lo matara. $(1$, p. 36$) \cdot{ }^{14}$

En la gradación "oración, responso, poema" se configura la fidelidad al kléos, al renombre obtenido por la muerte y convertido en poema, fiel al género discursivo que celebra un acontecimiento penoso, el capítulo de apertura insiste en la juventud y vulnerabilidad heroica, en el cabello cobrizo del guerrillero, como un rubio Aquiles moderno y en su pervivencia en un poema.

El capítulo final extrema la descripción de las condiciones de seguridad del aeropuerto donde el personaje aborda el avión, con lo cual su decisión de cambiar el vuelo media hora antes y que, no obstante ello, se concrete el asesinato, se vuelve destino inexplicable, fatal, inexorable. La decisión de este Aquiles colombiano expone la inerme existencia heroica, su decisión súbita no lo exime ni de error ni de culpa, así el personaje "detenido del talón por los dioses" ha ejercido una violencia extraordinaria, ha actuado, pero su propia existencia era inane, sostenida débilmente. La concepción del destino sigue sin fallas la línea homérica, el personaje es asesinado en el preciso inicio de un trayecto más justo, más humano; pero eso no redime, ni produce paralelo entre la acción y el destino: la lección del mito de los toneles continúa vigente. ${ }^{15} \mathrm{El}$ personaje se mueve aprisionado entre los conceptos que sirven de título a uno de los ensayos de Fuentes, entre su "voluntad" y su "fortuna". ${ }^{16}$ No hay vínculo entre la moralidad del sujeto y el destino que le acontece, por ello su muerte parece inexplicable en el preciso momento en que ha abandonado la violencia. La exacerbada muestra de vulnerabilidad se condensa en una línea - "Cayó Aquiles que hasta ese momento había vivido detenido del talón por los dioses" (19, p. 190) -, una esculpida frase que reúne el motivo mítico con la futilidad de la muerte a manos de un joven insignificante e inesperadamente

\footnotetext{
${ }^{14}$ Todas las citas de la novela corresponden a FUENTES, Carlos. Aquiles o el guerrillero y el asesino. México: FCE\&Alfaguara, 2016, única edición disponible hasta el momento.

${ }^{15}$ Cf. Iliada XXIV, 525-534.

${ }^{16}$ Se trata del ensayo La voluntad y la fortuna (2008). El título reedita la discusión sobre los límites de la acción heroica entre la propia decisión y el destino, que ha producido numerosos enfoques críticos. Véase Gill (1996, p. 29-40).
} 
cercano. Probablemente lo más homérico de este texto sea esta inevitabilidad de la muerte en el momento de conciliación humana.

\section{UN HEROÍSMO MODERNO: RELATO DE UN ITINERARIO “DE GUERRERO A GUERRILLERO"}

Mucho de la novela procede de un narrador que se comporta como lector desencantado y utiliza la literatura como clave para explicar la inefable realidad latinoamericana. De tal manera se suceden conversaciones con escritores como por ejemplo con Gaitán Durán, el editor de la revista Mito en una Bogotá que el narrador considera la "Atenas de América". Aún cuando el componente biográfico o autorreferencial resulte indiscutible, no menos notable resulta la tríada Épica, utopía y mito que subtitula el ensayo Valiente Mundo Nuevo. En ese ensayo se describe con certeza la desacralización del proceso de civilización que se proponía como proyecto final el grupo guerrillero. La épica corresponde a la etapa de lucha, la utopía al intento de construcción de una sociedad igualitaria en la selva y el mito se obtiene con la muerte del héroe. El antiguo guerrero épico deviene una versión derivada, disminuida, sacada de su grado original; pero con la clara intención de presentar a su personaje con los rasgos del colérico, por desencanto, contra la injusticia de un sistema. En un traslado comparativo, el guerrero del nuevo tiempo es el "guerrillero".

El propósito de embellecer la acción de una figura difícil de asimilar, pero capaz de despojarse de la violencia, se desarrolla como un análisis acerca de qué hechos posibilitan el surgimiento de este tipo de seres a lo largo de la historia:

Lo recordé esa mañana del asesinato de Aquiles, preguntándome si tenía derecho, como mexicano, ligado de todas estas maneras indirectas, lejanas o guarecidas, amistosamente próximas, a Colombia, a hablar de Colombia, a cantar la cólera del Aquiles colombiano, pero también, sin duda, a descubrir la pasión de Aquiles, sus amores, razones, dudas. Su itinerario. Más que su destino me interesaba su itinerario. Más que su ideología, me interesaba su viaje. De la familia a la guerrilla y de la guerrilla a la política y de la política a la muerte. Mi viajero había muerto. Este Aquiles fue, también, Odiseo. (2, p. 38-39).

Su personaje resulta integrado, simbiótico, una sumatoria de Aquiles y Odiseo, un personaje con la gloria de la violencia, pero viajero. El narrador desecha dos componentes de peso: su enfoque no es ideológico, es decir no habrá una toma de posición respecto del contenido político o las razones de justicia o injusticia de las acciones, sino una lectura del trayecto humano. El foco humano en sus amores, sus razones o sus dudas, deriva en la narración de una vida como un viaje. Compuesto de fuerza e inteligencia, Aquiles-Pizarro proyecta sobre su grupo la dimensión heroica en la asignación de nuevos nombres: "yo los llamaría Héctor, Diomedes, Cástor, Pelayo, como personajes que lo fueron de una Ilíada descalza: los compañeros de Aquiles. Los asimila la épica. Los hermana el destino: la muerte. Uno tras otro, cayeron en combate”. (2, p. 39). 
En la composición de esta figura heroica incide, sin duda, el ensayo subtitulado "La Iliada descalza" incluido en el volumen ya citado Valiente mundo nuevo. Épica, utopía y mito en la novela hispanoamericana, en que analiza la novela Los de abajo del mexicano Mariano Azuela, convirtiendo a la revolución mexicana en una Ilíada popular. Fuentes comenta en ese ensayo las opiniones críticas de Hegel y de Simone Weil, extrae de esta última la lección humana de la épica homérica "nunca admirar el poder, o detestar al enemigo, o despreciar a quienes sufren". Pero su mensaje personal es que los procesos de discordia violenta convierten a las personas en cosas, "cuando la gloria se desenmascara, nos muestra su rostro verdadero que es el de la muerte". ${ }^{17}$

Como una inversión de la estética de Ilíada, Aquiles-Pizarro no sólo muere en la novela, sino que muere fuera de combate, de un modo no heroico, en medio de turistas y viajeros. Este hecho lo distancia de su grupo, aunque de igual modo todos los personajes terminen muertos violentamente.

En su estudio sobre el Aquiles homérico, Callen King (1987, p. 171) señala que las sucesivas apropiaciones del personaje produjeron un proceso de erotización en la tradición medieval y renacentista que lo llevó paulatinamente a ser un amante de la guerra. Sin embargo, en la matriz homérica se hallan la juventud y humanidad rodeadas de una crisis afectiva marcada por la presencia maternal de Tetis. Es este aspecto homérico el que ha capturado a Fuentes, la intimidad del personaje violento y cómo llega a la muerte. Su Ilíada descalza, es la de los personajes desprovistos de protección, indefensos frente al destino, ya sea por su clase social, ya sea por estar excluidos de la nobleza tal como se infiere por la carencia de armadura.

Fuentes concede a la figura materna la misma relevancia que Tetis posee en Iliada. Se convierte en una presencia balsámica sin nombre propio, al igual que el padre y los hermanos, serán denominados por su función, como modo de universalizar la representación de cualquier padre o madre cuyos hijos se hubiesen involucrado en semejante violencia, o hubiesen sufrido prisión y tortura. Aquiles-Pizarro es además un narrador oral:

Aquiles no sabía si pensaba o decía esto, si lo escuchaban sus compañeros en la noche de la fogata o si se hablaba a sí mismo, pero al recordar a su madre le invadía a la vez una serenidad perpleja y un dolor apaciguante, como si la vida fuese un largo itinerario de dolor en dolor y lo único importante fuese el analgésico, el respiro entre pesar y pesar y eso era la madre, el respiro feliz. (2, p. 47).

El rasgo definitivo de su personaje es una intransigencia noble que le impide claudicar, la ubicación del guerrero entre el artista y el político, es el modelo de incorruptibilidad. La

\footnotetext{
${ }^{17}$ Cf. Fuentes (1990, p. 176) en que el escritor insiste en que Hispanoamérica no ha logrado recrear el círculo virtuoso de la literatura antigua entre mito, épica, tragedia, el círculo que restauraría los valores salvadores construyendo una historia colectiva en vez de un relato agonal. Probablemente la composición anular de su novela sobre Aquiles consista en el intento de recuperar esa circularidad virtuosa, que ya había sido ensayada por García Márquez en Cien años de soledad.
} 
muerte joven es necesaria, perentoria, en un sentido similar al de la bella muerte heroica en medio de una hazaña memorable: "entre el artista y el político está el guerrero mortal como un joven caudillo que debe morir joven para no corromperse, la promesa que debe serlo siempre, la figura de la colectividad individual... mi Aquiles cierto e imaginario a la vez" (3, p. 51).

De este modo resume Fuentes su concepción de itinerario a narrar: de dolor en dolor, el contenido patético de la trama no incorpora acontecimientos felices, el único instante de sosiego es el previo a la muerte del protagonista que, en una reintegración con su humanidad, recupera en su imaginación la normalidad de la vida recordando a sus mujeres, tal como el Aquiles homérico vuelve a la comida, al sueño y al sexo tras su cólera insomne. Pero el itinerario acaba de inmediato en la muerte. ${ }^{18}$

\section{Discordia y RELATO}

Un aspecto relevante de la novela reside en la difusión social de la discordia y de la cólera del guerrero como un proceso de envenenamiento en un claro contraste con la atribución de promisoria incorruptibilidad al personaje. Es interesante cómo el episodio del rapto de Briseida y el enfrentamiento con Agamenón se hallan trasladados a capítulos avanzados en los que la cautiva se llama Brígida y Agamenón recibe el nombre de Salomón Parras.

La selección del nombre del personaje homérico para el título, pospone la presencia de la ciudad implícita en la titulación de la epopeya, Ilíada. No obstante, la lucha del grupo guerrillero tiene como objetivo la ciudad. El elemento colectivo aparece a través de la ciudad de Bogotá que ha sido, como la civilizada Troya, una ciudad refinada, lujosa y alegre. Como Troya, Bogotá parece haber mostrado una sordera a los conflictos, una cierta transgresión, que se vuelca en la discordia entre los guerrilleros y el sistema, expresada como inevitable envenenamiento y como una vorágine violenta.

La reiteración de la íntima contradicción homérica entre la nobleza y la capacidad violenta del guerrero, ese aspecto de hibridez bestial ya notado por Nagy (1999, p. 26) adquiere en la versión de Fuentes las marcas de una educación de élite. Pizarro, en particular, ha recibido una educación especial y, sin embargo, su carácter guerrero se evidenciará en la producción de una economía de la rapiña mutua, tan primitiva como los raídes de los combatientes de Ilíada antes de llegar a Troya.

La violencia destructiva que se apodera de Bogotá causa la muerte de un número importante de intelectuales señalados por el narrador, su relato se vuelve memoria en un doble sentido: el del envenenamiento de una ciudad que no será narrado, tal como no se incluye en Ilíada el incendio de Troya y el más inofensivo - o menos comprometido - de

\footnotetext{
${ }^{18}$ Ilíada XXIV, 675. Como sostiene Alexander (2015, p. 19), la guerra de Troya "no modificó ninguna frontera, no ganó ningún territorio y no sirvió a ninguna causa", en ello reside el mensaje del poema: destacar la inutilidad de la guerra. En la novela de Fuentes la frustración es similar, la muerte del héroe no habilita una conclusión pacífica.
} 
memoria de los relatos, en que los héroes se vuelven narradores. La decisión de Fuentes en cuanto a la narración de la muerte de su héroe, recoge lo que Homero dejó marginado e inconcluso, para simbolizar en esa muerte los efectos y el valor ritual expurgativo.

La ciudad es presentada como una construcción cultural, "la Atenas de América" (3, p. 53) - según ya hemos mencionado - y, en consecuencia, las opiniones del narrador abundan en datos sobre la literatura latinoamericana: sobre Cintio Vitier, Lezama Lima, sobre Jorge Gaitán Durán el editor colombiano de la ya citada revista Mito. Con sutileza, Fuentes instala la concepción de la cólera y de la discordia como un concepto de raíz erótica que se vierte en la remozada versión de la vorágine - el título de la novela de otro latinoamericano, José Eustasio Rivera ${ }^{19}$ - en un modo allegado a la býbris y su consecuente áte, la violencia que lo deglute todo es "la novia envenenada" de Colombia. No se trata solamente de la feminización atribuida por Loraux (2003, p. 46) al cuerpo heroico herido en batalla, sino de la flagrante pasión similar a la pasión amorosa que lleva a combatir. En este sentido, el símil del canto XI de Ilíada en que el ímpetu guerrero de Agamenón es equiparado al fuego y los heridos pueden ser "mucho más queridos para los buitres que para sus mujeres" (...oi $\delta$ ' غ̇ं

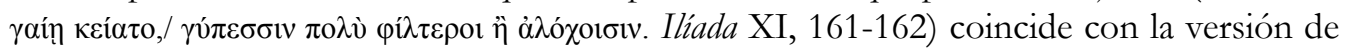
los efectos de la violencia imposibles de contener. ${ }^{20}$

La construcción de los demás personajes del grupo se funda en episodios históricos, como la muerte del padre de Cástor a manos de los liberales, con lo cual se diversifican las biografías y reaparece el tema de la rapiña. La alternancia en el relato de sucesos personales con la crónica histórica; por ejemplo, la revuelta de abril de 1948 en la que muere Gaitán Durán, implica una valoración de la historia como una literatura de lo contemporáneo. ${ }^{21}$ Tanto la muerte del padre de Cástor, como el encuentro del grupo con los niños guerrilleros entre los campesinos en el capítulo 5, sirven para establecer los hitos de la relación envenenada de Colombia con la violencia. Se trata de episodios que desde la colonia llegan a afectar el tiempo del narrador, es decir, se vuelven su causa o su paradigma. Un claro ejemplo de ello es la memoria de la revolución comunera de Socorro. ${ }^{22}$

Como sabemos, la ejecución cantada de acciones hazañosas no es patrimonio exclusivo del narrador homérico, el propio Aquiles aparece consciente del valor de estas narraciones en el mismo canto en el que Fénix desarrolla el relato pedagógico de la cólera de

\footnotetext{
${ }^{19}$ La novela de Rivera fue publicada en 1924 y constituye una apropiación de mitos grecolatinos, entre ellos Odisea, además de iniciar el ciclo de la narrativa sobre la violencia en la literatura colombiana del siglo XX, de manera que la referencia resulta por demás simbólica.

${ }^{20}$ Las citas del texto griego de Ilíada corresponden a la edición de Allen; Monro, 1920.

${ }^{21}$ Anticipadamente Fuentes propuso una visión crítica de la Literatura Latinoamericana que coincide con la propuesta de Jablonka (2016, p. 18) respecto de la historia como una "literatura de lo real". Fuentes trató deliberadamente de despojar a la épica de su sostén mítico y de conceder a su producción la potencialidad creativa de la memoria y el rigor del archivo.

${ }^{22}$ Una revolución surgida en 1781 que reunió a pobres, acomodados e indígenas contra la modificación tributaria impuesta por el rey Carlos III de Borbón y suele interpretarse como el inicio del proceso de independencia de Colombia. Varios de los líderes fueron ejecutados violentamente.
} 
Meleagro y su propia historia personal (IX, 430-605). El rol de narrador de relatos ejemplares le compete en la novela de Fuentes a Diomedes:

Ustedes son los primeros en oír mi historia. Agradezcánmela, que nuestras noches van a ser largas y mañana quién sabe si sigamos vivos... por lo menos debemos inspirar historias...

Los sorprendió la aurora de dedos rosados escuchando con fascinación a Diomedes el costeño y a los cuatro una especie de confusión les turbó el ánimo. ¿Ahora qué? Era la pregunta de los cuentos. También la de la acción. ¿Ahora qué? ¿qué sigue? Diomedes se quedó en la posición del narrador, sentado, pensativo y sonriente, ... (5, p. 79).

El texto citado reemplaza con eficiencia el diálogo con el thymós que en Homero brinda luz sobre la íntima deliberación. Por una parte, la versión de la audiencia suspendida en su percepción del tiempo, sorprendida por la aurora, ${ }^{23}$ la plena conciencia de actuar de modo de inspirar historias. Luego, la confusión, la pregunta por la continuación del relato, que es la pregunta por las secuencias y el desenlace que Fuentes dará a su propia versión de Aquiles. Vertida en la inofensiva frase de los cuentos (“¿Ahora qué?"), el anhelo por la continuación de la narración, desarrolla la posición del narrador inocuo: pensativo y sonriente.

\section{El carácter heroico de Aquiles-Pizarro}

Un episodio infantil concentra la presentación del colérico latinoamericano, que en un partido de fútbol ordena a su perro atacar a sus contrincantes, pero esta adaptación se enhebra con su entrenamiento de cuño espartano comentado en el capítulo 5, al tiempo que se introduce la referencia a su vulnerabilidad. Concebido romancescamente como un personaje que suma seducción y enfermedad, es como "el mejor de los aqueos", "el más guapo" (5, p. 83), pero en la descripción de Diomedes, Aquiles se vuelve realmente un meláncholos, es decir está "preso de una oscura tristeza" (6, p. 91). En secuencias previas Fuentes ya había equiparado al grupo con los conquistadores españoles para dar cuenta de su crueldad: "Eran guerreros hirsutos con largas crines de caballos"; son criollos, hijos de europeos, de educación europea, "dioses por fuera, niños por dentro" (6, p. 93).

La antítesis ínsita en el carácter del héroe que se halla tensionado entre su propensión a lo divino y su mortalidad aparece bien descripta en el contraste entre exterior e interior, que hace usufructo de la íntima contradicción de Aquiles, quien en el canto inicial de Ilíada se muestra potencialmente como el asesino de Agamenón y luego como un niño necesitado de su madre.

\footnotetext{
${ }^{23}$ Recupera el autor la frase formularia de Ilíada sobre la aurora. Citamos como ejemplo la línea del

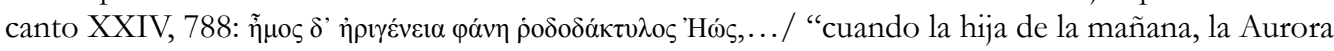
de rosados dedos apareció..."
} 
A modo de contrapunto, la ciudad que ha perdido las mejores figuras es opuesta a la selva, presentada como lo limpio, sustento y madre, de manera de habilitar la composición de la utopía en ese medio. También compara la revolución colombiana con la ocupación de México por Zapata para demostrar que se trataba de los empeños de intelectuales urbanos, a los que la selva enfrentaba con su propia ineficiencia e inutilidad.

Tres capítulos consecutivos, el 8, 9 y 10, insertan a Aquiles-Pizarro en su núcleo familiar, en su formación religiosa y en la complejidad del matrimonio de sus padres como ícono de los desacuerdos colombianos. Los hermanos apresados, "el abogado" y "el soldado" y su hermana, llamada "la niña", ilustran diversidad de destinos paradigmáticos. Sin duda, también en estos casos, la ausencia de nombre propio los vuelve representantes de destinos colectivos. El matrimonio de los padres, confrontados ideológicamente, expresa en el plano íntimo la misma dificultad registrada en lo social: el acuerdo inexistente. Tan desavenidos como Peleo y Tetis, quien se queja en el canto XVIII, 434-435 de Ilíada de la vejez de su esposo, los padres del personaje en la novela conceden un entorno familiar más completo y más complejo que el del poema homérico, pero igualmente discordante. La disparidad genética entre la diosa y el humano, entre la perennidad y la vejez, resulta tan insoluble como la oposición política, aunque nuevamente, parecen representar al carecer de nombres a las gentes comunes y honestas, y también sus dificultades de comprensión de los acontecimientos históricos con los cuales convivían.

Fuentes instala en esta novela a un personaje que había utilizado en Adán en Edén (2009), el del sacerdote Filopáter, al que adjudica el nombre de un discípulo de Aristóteles. Como versión latinoamericana del educador, el cura se vestía de modo informal y les martillaba la cabeza con ideas de trabajo, educación y libertad. Su condición de jesuita rebelde concuerda con la extrañeza del padre del Aquiles colombiano, un militar que leía a Theilhard de Chardin. Ha sido de particular interés para Fuentes el dedicar una extensión notable a esta polémica figura, que marca el itinerario de cómo el grupo de hermanos se involucra con la guerrilla y adhiere a la violencia y cómo Aquiles asesina al general Araujo. Los retratos de los opositores los presentan bajo los aspectos más execrables de corrupción, cuyas muertes inician una recurrencia de elementos funerales que culminarán con la repetición de la muerte del protagonista en el capítulo final de la novela. ${ }^{24}$

En la composición de Aquiles-Pizarro la inevitable vulnerabilidad heroica recrudece a partir del capítulo 12. Una parte de la anonimia de los personajes se explica por su inserción en la selva en la que adquirirán una nueva fama, un ser natural, más bestial. La profecía de la vida breve es desplazada por la moderna versión de una dolencia cardíaca:

Esa noche, Aquiles pidió reposo. Un ataque de disritmia cardíaca le afectó primero, mero preámbulo del episodio epiléptico que sobrevino más tarde, al amanecer, cuando Diomedes le metió una de las varas de la cruzada infantil entre los dientes y Aquiles, temblando,

\footnotetext{
${ }^{24}$ Una breve línea habla del funeral en que coincidieron el padre y Diomedes, bailando. El funeral se compone de danza y canto (11, p. 131).
} 
creyó que de verdad estaba naciendo de nuevo sólo que esta vez él nacía de sí mismo, Aquiles de Aquiles, al fin tocando la tierra de la montaña pero con un talón herido, violable, el talón que jamás se hundió, como el resto de su cuerpo, en las aguas del río Magdalena recorrido por la fiera rebelde de María Cano, la bautista que en vez de santos quería que los niños se llamaran Libertad y Progreso.

(12, p. 134).

El narrador no se arriesga a modificar el mito básico de la mortalidad sujeta a un detalle tan endeble e icónico de la debilidad vital como el hecho de que una parte insignificante del cuerpo estableciera el límite. El talón violable de Aquiles-Pizarro es instalado en medio de la historia colombiana, ya que ese talón parece no haber tocado las aguas del Leteo colombiano, el río Magdalena. Su mera nominación acarrea la memoria de otro episodio de discordia violenta simbólico de todos los desencuentros, el de la rebelde María Cano, quien lideró los reclamos de justicia por los derechos de las mujeres y de los obreros en 1928. Los recurrentes elementos de crónica adquieren un uso netamente homérico, validan con verosimilitud las restantes aseveraciones en las que, en realidad, el narrador reconstruye en su ficción cómo podía haber sido un ataque de la dolencia de su personaje, que hallaba un no ser provisorio y volvía a nacer.

\section{Una nueva versión de Briseida y de Agamenón}

En el diseño de la discordia hay una carencia notable en la novela que comienza a subsanarse a partir del capítulo 13 y que está determinada por una doble ausencia. Por una parte la ausencia de un personaje que reemplace con evidencia a Agamenón como antagonista y por otra parte, la ausencia del rapto de Briseida como desencadenante de la cólera de Aquiles.

La forma en que Fuentes decide involucrar a los personajes femeninos es, en parte, muy tradicional. Incorpora las figuras que se constituyen como parejas de los guerrilleros en matrimonios que, en algunos casos, se asimilan al funcionamiento de Héctor y Andrómaca. ${ }^{25}$ En otros momentos el recurso es totalmente paródico o anticonvencional. Un ejemplo del primer caso se encuentra en la relación de Pelayo y Agustina. Anticonvencional es la intromisión de Brígida, cuyo nombre memora fonéticamente a Briseida. El episodio reelabora

\footnotetext{
${ }^{25}$ El capítulo 13 permite la irrupción de la nostalgia por la normalidad de la vida. Pelayo sueña que no quiere olvidarse de cómo es el cuerpo de una mujer. La pareja de Cástor es descripta como poseedora de "una belleza morisca, andaluza". El amor de estos personajes, surgido al amparo de la librería Buchholz de Bogotá y de la lectura de Rayuela de Cortázar sirve para introducir la imagen de la sofisticación cultural de la ciudad. Troya está ausente de este relato excepto en este contemplar Latinoamérica como un espacio devorado por la pampa y la selva, en el que vivir en la construcción cultural que la ciudad implicaba era un desafío a la imaginación. Es un capítulo construido a expensas de la literatura latinoamericana: los personajes pueden ser devorados por la selva, como en la novela de José Eustasio Rivera, La vorágine, o interrogarse si, como en la novela de Cortázar, encontrarían a la Maga.
} 
la obtención de la muchacha como botín o premio antes del ataque a Troya, de un modo cáustico. Fuentes recrea la casona de un proxeneta, el manipulador de un pueblo, Máximo Vale, un viejo al que solo servían y custodiaban mujeres. Maximo Vale creía que nadie agredería a su reducto de mujeres y, no obstante, sufre un ataque del grupo guerrillero que lo deja indefenso. Es el grupo de mujeres el que habilita el riesgo en una actuación que las vuelve estratégicamente dolosas, desde el interior de la casa:

Rodearon la casa cuando ya todas las mujeres estaban avisadas en secreto de la hora y el día exacto del ataque. Ellas fueron las yeguas de Troya que abrieron los portones de la casona del viejo agiotista un mediodía oloroso a mangos jugosos que empezaban a reventarse dentro de sus pieles, ... (13, p. 141-142).

El comportamiento femenino, una versión desestilizada de Helena poniendo en riesgo a los griegos que estaban en el interior de caballo (Odisea, IV, 279-280), desarrolla otra secuencia ausente en Ilíada, saber concretamente cómo llegó Brígida/Briseida hasta Aquiles:

La Brígida les abrió la puerta y ella fue lo primero que vio Aquiles al entrar como un ventarrón armado a la Troya de Máximo Vale. (13, p. 142).

..., qué bárbara, se dijo Aquiles, qué salvaje hembra, soy la Brígida, se anunció, los estábamos esperando; ... (13, p. 143).

...nunca supo... si la mujer... estaba allí por propia voluntad o era parte de un botín que él no deseaba tomar como tal pero que no podía resistir, así lo llamase la Brígida o la tomase él, ... (13, p. 143).

Sólo una noche se acostó la Brígida con Aquiles. Al amanecer una cabalgata que enmudeció las campanas de la iglesia pasó por el pueblo en medio de un volar de pájaros silenciosos que huían en sentido contrario. (13, p. 145).

La denominación coloquial e incluso propia de su situación social, "la Brígida", con la anteposición del artículo, hace del personaje una versión popularizada. Sin embargo, su rapto tiene las mismas consecuencias emocionales graves de Ilíada:

(...) desafiando a las campanas o a los pájaros a que silenciaran su cólera, la pérdida de su botín de guerra, su premio, su amor, su Brígida, gritando enfurecido que sí, era cierto, él creía tener derecho a todo, el amor y la revolución, el botín de guerra y la gloria de la muerte, ... Iba a blasfemar... pero Aquiles no quería que sus insultos obligaran a Dios a colmarlo de bienes. Prefirió clamar contra los que le quitaron a la Brígida, y llevar contra ellos la guerra, ahora sí confundidas su urgencia de actuar y su urgencia de amar: mi premio, mi amor, mi Brígida... (13, p. 145). 
El episodio de Brígida pospuesto más allá de la mitad de la novela, implica una selección intencionada de la cólera causada por este personaje que distrae al guerrillero de su objetivo fundamental. Una sofisticada reelaboración de la simbiosis de motivos eróticos/ heroicos presente en Ilíada. El estatuto de Briseida como premio o botín de guerra, se mezcla con los sentimientos amorosos y la parodia de la súplica que su madre lleva a Zeus, invierte en orgullo la promesa de compensación obtenida en Homero. También debe considerarse que Salomón Parras, el raptor de Brígida, como un Agamenón ubicado en la selva, coincide en la similitud fonética entre nombres, pero sus razones son absolutamente diferentes.

Salomón/Agamenón aparece por primera vez en el capítulo 14, como un líder cesáreo explícitamente involucrado en dividir e imperar. El personaje había constituido un miniestado en medio de la selva, pero el rasgo homérico más notable que la novela recupera es su codicia ("la voracidad de los caudillos locales animada por los políticos de Bogotá, los campesinos liberales despojados por los conservadores...”), el principio de los basiléas dorophágous que transita de Homero a Hesíodo confronta campesinado y caudillos. ${ }^{26}$ Salomón Parras era un antiguo minero devenido vendedor de coca y explotador de esmeraldas. El rapto de Brígida le añade gloria.

El diálogo entre Salomón Parras y Aquiles opone a un adulto corrompido por las ganancias de la guerra con un joven idealista al que Parras ve como un niño inocente. El sistema de valores disfunciona, indefenso, por lo crematístico de Parras que, como Agamenón, habla a Aquiles en términos pragmáticos y cuantitativos: "imagínese en una justa medieval, o ya que lo llaman Aquiles, en una playa frente al mar jarde Troya!, desafiando a Héctor... $(14$, p. 151). Finalmente, Parras lo vence en un juego de azar.

\section{EL ASESINO}

Conforme a la disyunción expresada por el título, el asesino recibe mayor atención en los capítulos finales, a partir del relato del pasado de un grupo de sicarios compuesto por los personajes de Cóndor, Kike y Lamparilla. A partir del capítulo 15 ellos ilustran un modo de guerra mercenaria que busca algún ascenso social. Parece también una desordenada intromisión, similar a la inserción de un episodio como la Dolonía en el contexto narrativo de Ilíada. Sin embargo, el engaño a Cóndor y su muerte, cumplen la función deíctica de la falta de código heroico.

El asesino carece de estatura heroica, no tiene de ningún modo la dimensión de su contrincante, pero este agón desparejo, al tiempo que destituye la idea de algún tipo de excelencia condigna explica la tragedia latinoamericana: un líder con intenciones nobles es asesinado por una suma irrisoria y por un personaje insignificante.

La analepsis del pasado ofrecida por el capítulo 17 ofrece varias ironías trágicas. El relato de la infancia de Kike, sin pelo y harapiento, se proyecta a la ironía extrema: el héroe

\footnotetext{
${ }^{26}$ Cf. Hesíodo, Trabajos y Días, 38-39. También los reclamos de Tersites a Agamenón en Ilíada, II, 225-242.
} 
Aquiles-Pizarro es asesinado por el niño desvalido que su madre educó como maestra en una ciudad costeña. También los vínculos de Kike con la hija de la familia rica para la cual trabajaba su madre, derivan en un beneficio económico que señala las razones para asesinar y es la respuesta desolada a la situación colombiana. ${ }^{27}$

Finalmente, como otra deuda con Ilíada, el narrador introduce antes del final, al personaje de un anciano, denominado por un apodo como los demás personajes, el Termómetro. Este personaje asume las características nobles y piadosas de Príamo, pero al recibir el cadáver de su hijo acribillado en una carreta tarda en descubrir que se le ha entregado una suma valiosa en compensación y cuando lo descubre, igualmente se corrompe.

\section{Conclusiones}

En la lectura de Fuentes, la discordia de este Aquiles moderno involucra dos vertientes, la amorosa y la del anhelo de reformular las estructuras sociales, por ello no acepta sin más la propuesta homérica, la subvierte, la interrumpe y la distorsiona. Un primer nivel de polémica distorsión se efectúa al elegir la narración de aquello que Homero deja en el nivel proléptico, es decir, al decidir narrar la muerte de Aquiles. Como el movimiento temporal es retrospectivo, la discordia contenida en la sociedad colombiana representada se enraíza en otras discordias latinoamericanas; por ejemplo, la de la revolución de los comuneros o la de Maria Cano. Al fin, el relato de la cólera del personaje, ya sea por su amor a Brígida o por su rechazo a la injusticia, hace de la novela una suerte de mitografía, una escritura que conserva la muerte del héroe que Homero no narró. Por la misma razón, ella se vuelve una suerte de Aquileida latinoamericana, trágica sin igual, porque la discordia de los dispares trayectos formativos de los personajes los deja a ambos muertos: al guerrillero y al asesino. Resulta una doble provocación de piedad, la de quien procuró abandonar la violencia e iniciar una refundación pacífica y la que causa el destino incorregible de su disminuido adversario, conmovido, sin embargo, por su madre.

Sorteadas las peculiaridades genéticas de la novela que, por azar del destino la aproximan a la historia de los textos homéricos, su composición anular, su desmitificación del héroe y de su antagonista produce, no obstante, una nueva mitificación: no hay un vencedor y un vencido. Fiel al cuño homérico hallamos dos muertes casi sin intervalo temporal: un ícono de la concepción de Fuentes acerca de los destinos latinoamericanos aprisionados en una fraternidad imposible.

\footnotetext{
${ }^{27}$ Las referencias a la infancia continúan en el capítulo 18 cuando Pelayo rehúsa ayudar a otro niño que le roba el reloj desde una alcantarilla.
} 


\section{REFERENCIAS}

AGUILAR, Carlos Rutilio. Carlos Fuentes: la construcción de una gran obra narrativa. Revista Levadura, 20 abr. 2018. Sección Cultura. Disponible en: http://revistalevadura. $\mathrm{mx} / 2018 / 04 / 20 /$ carlos-fuentes-la-construccion-una-gran-obra-narrativa/. Consultado el: 4 feb. 2019.

ALEXANDER, Caroline. La guerra que mató a Aquiles. Madrid: Acantilado, 2015.

ALLEN, William; MONRO, David. Homeri Opera. Oxford: Oxford University Press, 1920.

ANADÓN, José. Entrevista a Carlos Fuentes (1980). Revista Iberoamericana, Pittsburgh, v. 49, n. 123-124, p. 621-30, abr.-sept. 1983.

AUSTIN, Norman. The function of digressions in The Iliad. In: WRIGHT, John (Ed.). Essays on the Iliad. Bloomington: Indiana University Press, 1978, p. 70-84.

BRODY, Robert; ROSSMAN, Charles (Ed.). Carlos Fuentes: A Critical View. Austin: University of Texas Press, 1982.

CALLEN KING, Katherine. Achilles. Paradigms of War Hero from Homer to the Middle Ages. Berkeley: University of California Press, 1987.

DÁVILA, Luis. Carlos Fuentes y su concepto de la novela. Revista Iberoamericana, Pittsburgh, v. 47, n. 116-117, p. 73-8, jul.-dic. 1981.

FUENTES, Carlos. La voluntady la fortuna. México: Alfaguara, 2008.

FUENTES, Carlos. Valiente mundo nuevo. Épica, utopia y mito en la novela hispanoamericana. México: Fondo de Cultura Económica, 1990.

GARCÍA GUTIÉRREZ, Georgina. Hollywood, política y Literatura en Carlos Fuentes. Revista Tempo, nov. 1999. Disponible en: http://www.uam.mx/difusion/revista/nov99/garcia. html. Consultado el 10 enero 2019.

GIACOMAN, Helmy. Homenaje a Carlos Fuentes. New York: Las Américas, 1971.

GILL, Christopher. Personality in Greek Epic, Tragedy, and Philosophy: The Self in Dialogue. New York: Oxford University Press, 1996.

GONZÁLEZ ECHEVARRÍA, Roberto. Myth and Archive. A theory of Latin American narrative. Cambridge: Cambridge University Press, 1990.

GYURKO, Lanin A. Magic Lens. The Transformation of the Visual Arts in the Narrative World of Carlos Fuentes. Nueva Orleáns: University Press of the South, 2010.

GYURKO, Lanin A. Spellbound: Alfred Hitchcock and Carlos Fuentes. Nueva Orleáns: University Press of the South, 2012.

GYURKO, Lanin A. The Shattered Screen. Myth and Demythification in the Art of Carlos Fuentes and Billy Wilder. Nueva Orleáns: University Press of the South, 2009. 
LA DISCORDIA DE ILÍADA EN LA NOVELA AQUILES O EL GUERRILLERO Y EL ASESINO

DE CARLOS FUENTES

HEIDMANN, Ute. Poétiques comparées des mythes. De l'Antiquité à la Modernité. Lausanne: Editions Payot Lausanne, 2003.

IBSEN, Kristine. Memoria y deseo: Carlos Fuentes y el pacto de la lectura. México: Fondo de Cultura Económica, 2003.

JABLONKA, Ivan. La historia es una literatura contemporánea. Manifiesto por las ciencias sociales. Buenos Aires: Fondo de Cultura Económica, 2016.

LORAUX, Nicole. Las experiencias de Tiresias. Buenos Aires: Editorial Biblos, 2003.

LOWE, Nicholas J. Tragic and Homeric Ironies. In: SILK, Michael (Ed.). Tragedy and the Tragic. Greek Theatre and Beyond. Oxford: Oxford University Press, 1996, p. 520-33.

MUELLER, Martin. Knowledge and Delusion in The Iliad. In: WRIGHT, John (Ed.). Essays on the Iliad. Bloomington: Indiana University Press, 1978, p. 105-23.

NAGY, Gregory. The Best of Achaeans. Washington: Center for Hellenic Studies, 1999. Disponible en: http://nrs.harvard.edu/urn-3:hul.ebook:CHS_NagyG.The_Best_of_the_ Achaeans.1999. Consultado el 1 feb. 2019.

ORTEGA, Julio. Carlos Fuentes, Cambio de Piel. In: GIACOMAN, Helmy. Homenaje a Carlos Fuentes. New York: Las Américas, 1971, p. 107-24.

ORTEGA, Julio. Carlos Fuentes: Para recuperar la tradición de La Mancha. Revista Iberoamericana, Pittsburgh, v. 55, n. 148-149, p. 637-54, jul.-dic. 1989.

ORTEGA, Julio. Retrato de Carlos Fuentes. Barcelona: Círculo de Lectores, 1995.

PERILLI, Carmen. Entre Molinos de viento y metrópolis de cartón: la novela de Carlos Fuentes. Revista Espéculo, 2001. Disponible en: http://www.ucm.es/info/especulo/ numero18/c_fuentes.html. Consultado el 10 enero 2019.

SEAFORD, Richard. Reciprocity and Ritual. Homer and Tragedy in the Developing City-State. Oxford: Clarendon Press, 1994.

SOMMER, Doris. Irresistible romance: the foundational fictions of Latin America. In: BHABHA, Homi K. (Ed.). Nation and Narration. London: Routledge, 1990, p. 71-98.

SOSNOWSKI, Saúl. Entrevista a Carlos Fuentes. Eco, Bogotá, v. 45, 1981, p. 515-49.

VAN DELDEN, Maarten. Carlos Fuentes, Mexico, and Modernity. Nashville: Vanderbilt University Press, 1998.

VILLALOBOS, José Pablo. Supervivencia, renovación y muerte: Carlos Fuentes y las genealogías del tiempo. In:___ La imaginación genealógica: Herencia y escritura en México. Colima: Universidad de Colima, 2006, p. 93-136.

WILLIAMS, Raymond Leslie. The Writings of Carlos Fuentes. Austin: The University of Texas Press, 1996. 
ZECCHIN DE FASANO, Graciela Cristina. Memoria y funeral: Príamo y Aquiles en Iliada XXIV. 472-551. Revista Synthesis, La Plata, v. 7, p. 57-68, 2000. Disponible en: http://www.memoria.fahce.unlp.edu.ar/art_revistas/pr.2861/pr.2861.pdf

ZECCHIN DE FASANO, Graciela Cristina. Temor y Compasión en los poemas homéricos. Revista Synthesis, La Plata, v. 9, p. 109-28, 2002. Disponible en:

http://www.memoria.fahce.unlp.edu.ar/art_revistas/pr.295/pr.295.pdf 